\title{
Sphingosine kinase 1 and sphingosine-1- phosphate receptor 2 are vital to recovery from anaphylactic shock in mice
}

\author{
Ana Olivera, ${ }^{1}$ Christoph Eisner, ${ }^{2}$ Yoshiaki Kitamura, ${ }^{1}$ Sandra Dillahunt, ${ }^{1}$ Laura Allende, ${ }^{3}$ \\ Galina Tuymetova, ${ }^{3}$ Wendy Watford, ${ }^{4}$ Francoise Meylan, ${ }^{5}$ Susanne C. Diesner, ${ }^{1}$ Lingli Li, ${ }^{2}$ \\ Jurgen Schnermann, ${ }^{2}$ Richard L. Proia, ${ }^{3}$ and Juan Rivera ${ }^{1}$
}

${ }^{1}$ Laboratory of Molecular Immunogenetics, National Institute of Arthritis and Musculoskeletal and Skin Diseases (NIAMS), NIH, Bethesda, Maryland, USA. ${ }^{2}$ Kidney Diseases Branch and ${ }^{3}$ Genetics of Development and Disease Branch, NIDDK, NIH, Bethesda, Maryland, USA.

${ }^{4}$ Molecular Immunology and Inflammation Branch, and ${ }^{5}$ Autoimmunity Branch, NIAMS, NIH, Bethesda, Maryland, USA.

\begin{abstract}
Sphingosine kinase 1 (SphK1) and SphK2 are ubiquitous enzymes that generate sphingosine-1-phosphate (S1P), a ligand for a family of G protein-coupled receptors (S1PR1-S1PR5) with important functions in the vascular and immune systems. Here we explore the role of these kinases and receptors in recovery from anaphylaxis in mice. We found that $S p h k 2^{-/-}$mice had a rapid recovery from anaphylaxis. In contrast, $S p h k 1^{-/-}$mice showed poor recovery from anaphylaxis and delayed histamine clearance. Injection of S1P into Sphk1 ${ }^{-/-}$mice increased histamine clearance and promoted recovery from anaphylaxis. Adoptive cell transfer experiments demonstrated that SphK1 activity was required in both the hematopoietic and nonhematopoietic compartments for recovery from anaphylaxis. Mice lacking the S1P receptor S1PR2 also showed a delay in plasma histamine clearance and a poor recovery from anaphylaxis. However, S1P did not promote the recovery of $S 1 p r 2^{-/-}$mice from anaphylaxis, whereas $S 1 p r 2^{+/-}$mice showed partial recovery. Unlike $S p h k 2^{-/-}$mice, $S p h k 1^{-/-}$ and $S 1 \mathrm{pr}^{-/-}$mice had severe hypotension during anaphylaxis. Thus, SphK1-produced S1P regulates blood pressure, histamine clearance, and recovery from anaphylaxis in a manner that involves S1PR2. This suggests that specific S1PR2 agonists may serve to counteract the vasodilation associated with anaphylactic shock.
\end{abstract}

\section{Introduction}

Anaphylaxis is a serious allergic reaction that typically involves the activation of mast cells and basophils (1-3). Unlike other allergic reactions involving mast cells, anaphylaxis affects the function of multiple organ systems, including the respiratory and circulatory systems, and thus it is a severe and life-threatening episode, although rarely lethal. Usually, the trigger is an allergen (such as insect venom, food, and medication), distributed systemically. In most cases, the antigen $(\mathrm{Ag})$ is recognized by $\operatorname{IgE}$ antibodies bound to the high-affinity receptor for IgE (FceRI) expressed on plasma membrane of mast cells. Aggregation of FceRI by IgE/Ag initiates signals that lead to the release of multiple allergic mediators contained in mast cell granules, and these mediators are responsible for the initiation of the immediate hypersensitivity that may result in anaphylaxis (4). As implied, immediate hypersensitivity does not necessarily result in anaphylaxis, suggesting there are risk factors or other determinants of susceptibility to this event (5).

Mast cells are known for their plasticity, and environmental cues may alter their responsiveness to an Ag or may alter the type of constituents in mast cell granules and thus the amount or type of allergic mediators released. These environmentally induced alterations in the mast cell phenotype could be one factor that may influence susceptibility or severity of anaphylaxis. There is increasing evidence that the bioactive lipid sphingosine-1-phosphate (S1P) may be one of these environmental cues. This lipid is produced by 2 known sphingosine kinases (SphK1 and SphK2) and has important functions in the immune and vascular systems

Conflict of interest: The authors have declared that no conflict of interest exists. Citation for this article: J Clin Invest. 2010;120(5):1429-1440. doi:10.1172/JCI40659. by binding to and signaling through 5 distinct $G$ protein-coupled receptors (GPCR), S1PR1-S1PR5 (6). In allergic asthma, S1P levels were found to be elevated in the bronchial fluids after an allergenic challenge $(7,8)$. Moreover, antagonism of S1PRs by the drug FTY720 has been shown to abrogate experimental asthma, by altering dendritic cell function (9), and suppress the development of allergic conjunctivitis in mice (10).

It is well recognized that acute treatment of mast cells with S1P synergizes with the effect of FceRI, enhancing mast cell responsiveness, whereas treatment of mast cells with sphingosine causes nonresponsiveness (11). Nonetheless, a recent study (12) demonstrated that $\mathrm{S} 1 \mathrm{P}$ is not required for the induction of anaphylaxis. Mice deficient in both SphK1 and SphK2 failed to produce S1P but were susceptible to passive systemic anaphylaxis, as measured by decreased survival (12). This suggests that $\mathrm{S} 1 \mathrm{P}$ is not necessary for mast cell degranulation and induction of anaphylaxis, a finding which is consistent with the prior findings that S1P acts in synergy with FceRI activation $(11,13,14)$ and that low S1P production in FceRI-stimulated mast cells (15) or the absence of the S1PR2 receptor (16) decreases, but does not abrogate, mast cell degranulation. However, in a mouse model of anaphylaxis, we found that S1P levels correlated with the amount of circulating histamine (15), suggesting that it may influence mast cell responsiveness in vivo. We proposed that the levels of S1P present in serum or in the local environment was a determinant affecting anaphylaxis and demonstrated that in vivo manipulation of circulating S1P altered the amounts of histamine in the circulation during anaphylaxis (15). Consistent with this view, another study showed that exposure of cord-blood human mast cell progenitors to S1P expedited their differentiation into fully mature connective tissue-type mast cells 

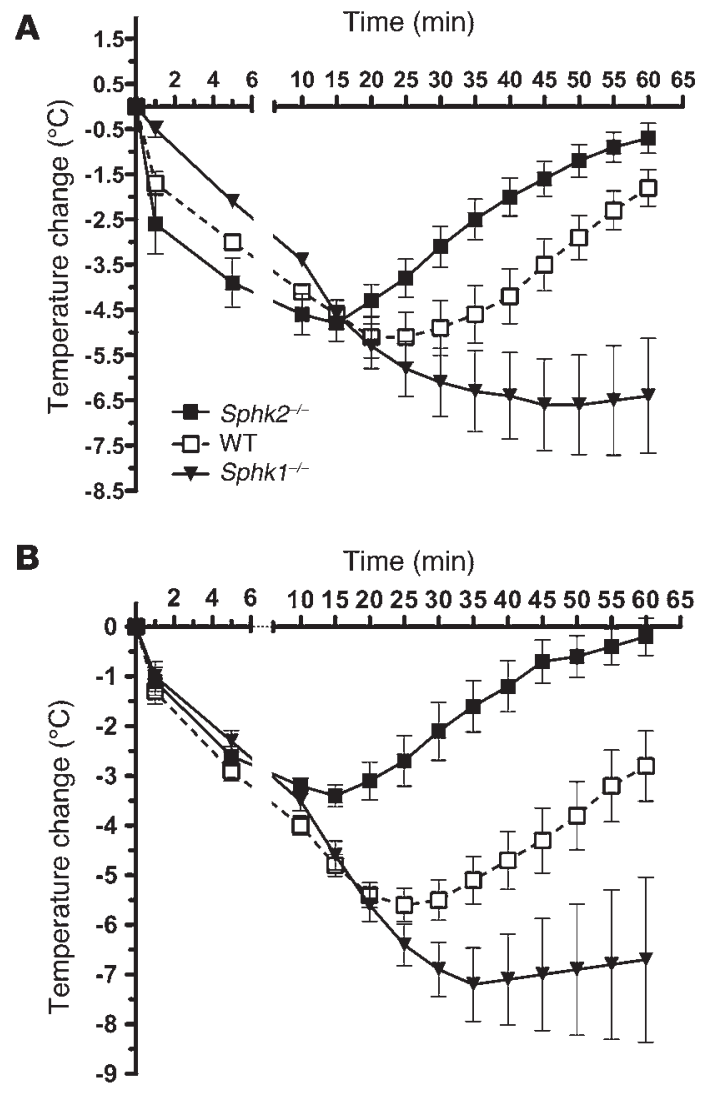

and caused higher expression of chymase as well as an enhanced degranulation and chemokine release (17). Thus, the production of S1P and exposure of mast cells to S1P may be important factors influencing allergic and anaphylactic responses.

Since S1P mediates much of its activity through cell surfaceexpressed S1P receptors (6), it is also likely that these receptors may influence mast cell responsiveness and the role of these cells in disease. Mast cells express S1PR1 and S1PR2 receptors, and these receptors function in chemotaxis and degranulation, respectively (16). Beyond their potential role in mast cell function, S1PR1, S1PR2, and S1PR3 receptors are known to regulate the vascular system, affecting vascular tone, vascular permeability, and heart rate (18-20). Therefore, it is possible that S1P levels in the circulation or the $\mathrm{S} 1 \mathrm{P}$ produced during anaphylaxis could influence the severity of the response in a manner that is mast cell independent.

Here we explored this possibility. In vivo studies showed that S1P is not only involved in the mast cell-dependent onset of anaphylaxis, as previously described (15), but also in recovery from anaphylaxis in a mast cell-independent manner. S1P production, via SphK1 activation from both a hematopoietic and a nonhematopoietic cell source, is a crucial step for the clearance of histamine, a mediator of anaphylactic shock (21). The S1PR2 receptor participates in this counterregulatory feedback loop by controlling the drop in blood pressure characteristic of allergen-induced anaphylaxis and thus renal blood flow and clearance of plasma histamine. The findings provide evidence of what we believe to be a novel mechanism for the increased severity of anaphylactic shock and histamine intolerance. Development of specific S1PR2 agonists may prove a useful alternative for anaphylaxis treatment $(5,22,23)$.

\section{Figure 1}

Differences in the recovery from anaphylaxis between Sphk1-/- and Sphk2--- mice are mast cell-independent. (A) WT, Sphk1--, and Sphk $2^{-/-}$mice were injected (i.v.) with DNP-specific IgE $(3 \mu \mathrm{g})$. After 24 hours, mice were challenged with $\mathrm{Ag}\left(250 \mu \mathrm{g} \mathrm{DNP}_{36}-\mathrm{HSA}\right)$ to induce systemic anaphylaxis. Body temperature changes during the anaphylactic shock induced by $\mathrm{Ag}$ were measured as described in Methods. Mice ( $n=12 /$ group) were euthanized after 60 minutes. The gap in the $x$ axis at 6 minutes denotes a change in scale. (B) Anaphylaxis was induced by injecting histamine (5 umol) into WT, Sphk $1^{-1-}$, and Sphk2-/- mice ( $n=7-10 /$ group). This concentration of histamine showed a similar anaphylactic response as that induced by $\mathrm{lgE} / \mathrm{Ag}$ in

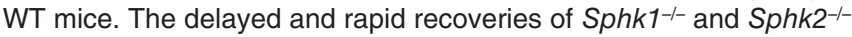
mice, respectively, were maintained. Body temperature was monitored as described in Methods.

\section{Results}

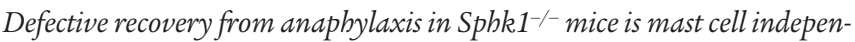
dent. We previously hypothesized that S1P could be a factor determining the susceptibility to or severity of anaphylaxis, based on the effect of S1P in increasing the responsiveness of mast cells. As previously reported (15) and confirmed herein, the plasma histamine concentration after passive systemic anaphylactic challenge (1.5 minutes) indicated a lower mast cell responsiveness in Sphk1-/versus Sphk2 $2^{-/-}$mice (Supplemental Figure 1A; supplemental material available online with this article; doi:10.1172/JCI40659DS1). Since we previously demonstrated that the circulating levels of

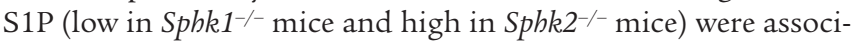
ated with the amount of circulating histamine, we asked whether differences in the circulating levels of S1P might also influence recovery from anaphylaxis. Therefore, body temperature was measured over a period of 60 minutes after induction of anaphylaxis. In mice, anaphylactic shock is manifested by an acute hypothermia $(24,25)$ mediated by histamine (21) released from mast cells, primarily through its effects on the hypothalamus (26). The drop in body temperature is associated with many of the symptoms of systemic anaphylaxis and shock, and thus it is useful in the measurement of the intensity of the anaphylactic episode. While the

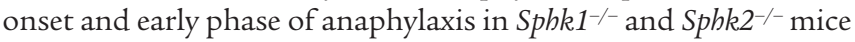
correlated with the amount of histamine released (Figure 1A and Supplemental Figure 1), major differences were observed in the body temperature 10-15 minutes after challenge (Figure 1A). While WT mice began to recover body temperature after 25 minutes, Sphk1 $1^{-/}$mice continued to lose body temperature, although in some cases a minimal recovery was seen within 60 minutes after challenge. In contrast, Sphk2-/- mice showed a maximum loss of body temperature within 15 minutes and a rapid recovery relative to WT mice (Figure 1A).

To understand whether mast cells contributed to the differences observed, we bypassed the contribution of the mast cells as initiators of anaphylaxis by inducing systemic anaphylaxis with a bolus of histamine that reproduced the loss of body temperature induced in WT mice by an IgE/Ag challenge. This was based on the previous finding that histamine production by mast cells was both necessary and sufficient for the loss of body temperature and the decreased respiratory rate during IgE/Ag-induced passive systemic anaphylaxis (21). In agreement, we demonstrated that IgE/Ag does not trigger a systemic anaphylactic response in mast cell-deficient mice ( $W^{\text {sh }} / W^{\text {sh }}$ mice), whereas these mice undergo a systemic anaphylactic reaction to a direct challenge with histamine (Supple- 
A
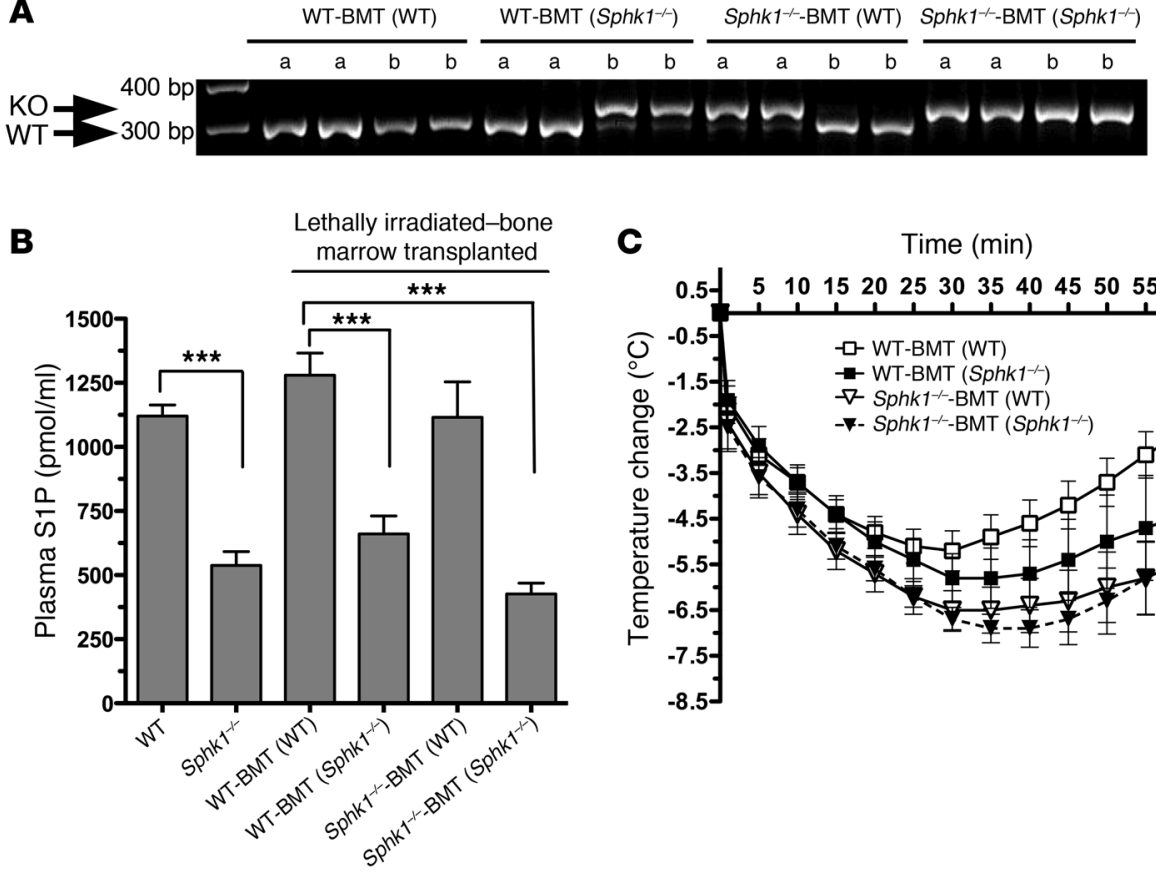

C

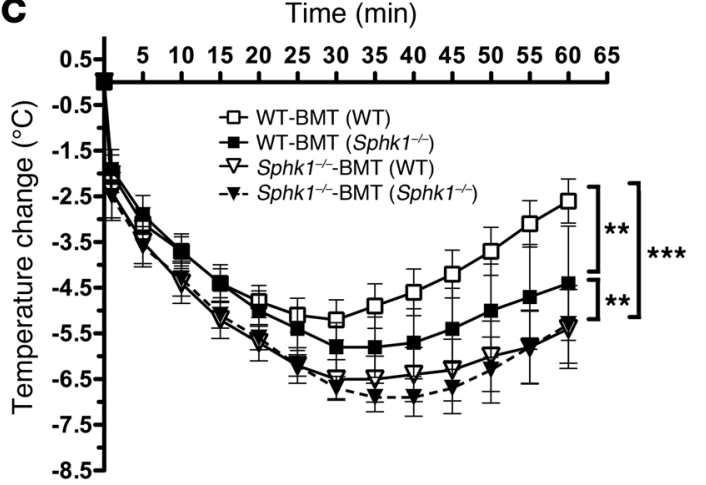

sible for their poor recovery from anaphylaxis, bone marrow cells from WT mice were transplanted to lethally irradiated Sphk1 $1^{-/-}$mice, producing a chimera in which SphK1 was deleted in the periphery but present in the hematopoietic compartment [Sphk1-/-BMT(WT) mice] (Figure 2A). These mice had normal levels of circulating S1P (Figure 2B) but showed a more severe anaphylactic response and a slower rate of recovery than WT mice transplanted with WT bone marrow [WT-BMT(WT) mice] (Figure 2C). The response of the Sphk1-/-BMT(WT) mice was similar to the anaphylactic

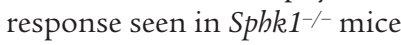

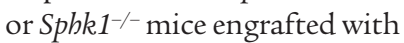

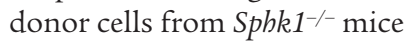

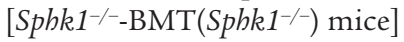
(Figure 2C), which had low levels of circulating S1P (Figure $2 \mathrm{~B}$ ). This clearly indicated that restoring the circulating levels of S1P in Sphk1 $1^{-/-}$mice is not sufficient for proper recovery from anaphylaxis and that the absence of SphK1 expression in a nonhematopoietic compartment was detrimental to recovery from anaphylactic shock.

To more directly assess the contribution of SphK1 in the hematopoietic compartment, we also generated chimeras of WT mice transplanted with bone marrow cells from $S p h k 1^{-/-}$

mental Figure 2), demonstrating that the anaphylaxis induced by histamine is mast cell independent. A histamine challenge did not mirror the differences seen in the onset of anaphylaxis (within

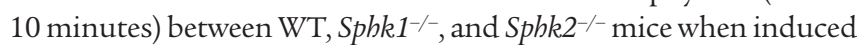
by $\operatorname{IgE} / \mathrm{Ag}$ (Figure $1 \mathrm{~A}$ versus Figure 1B), demonstrating that these differences are due to mast cell responsiveness. However, the late phase of anaphylaxis (recovery) brought on by the histamine challenge mirrored the recovery of the respective genotypes when challenged with $\mathrm{IgE} / \mathrm{Ag}$ (Figure $1 \mathrm{~A}$ versus Figure $1 \mathrm{~B}$ ). These results showed the requirement for non-mast cell SphK1 activity in the recovery from anaphylaxis.

Sphk1 in both hematopoietic and nonhematopoietic compartments is critical for the recovery from anaphylaxis. The circulating levels of S1P in Sphk1 $1^{-/-}$mice are about half of those in WT mice (refs. 15, 27, 28; Figure 2). In contrast, Sphk2-/- mice have higher levels of circulating S1P than WT mice (possibly due to increased SphK1 activity in the rbc of these mice; ref. 15). To test whether the constitutively reduced levels of S1P in the circulation of Sphk1 $1^{-/-}$mice was respon- mice [WT-BMT $\left(S p h k 1^{-/-}\right)$mice] (Figure 2A). Plasma S1P levels in these mice were reduced relative to WT mice (Figure 2B). Histamine challenge of these mice (Figure 2C) showed an impaired recovery relative to WT-BMT(WT) mice, though not as severe as

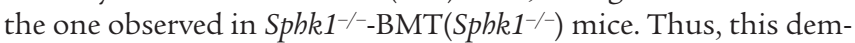
onstrated that SphK1 in the hematopoietic compartment is needed for normal recovery from anaphylaxis. Collectively, the findings demonstrate that SphK1, in both the hematopoietic and nonhematopoietic compartments, plays a role in the recovery from anaphylaxis. However, SphK1 in the nonhematopoietic compartment appears to be dominant or downstream of the role of SphK1 in the

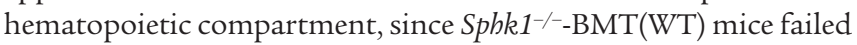
to recover from anaphylaxis.

Histamine-induced S1P production via SphK1 counteracts anaphylaxis. Histamine was shown to increase the expression and activity of SphK1 in human endothelial cells (29). Thus, we hypothesized that histamine, acting through its receptors in the hematopoietic or nonhematopoietic compartment, might activate SphK1 to form S1P 
A

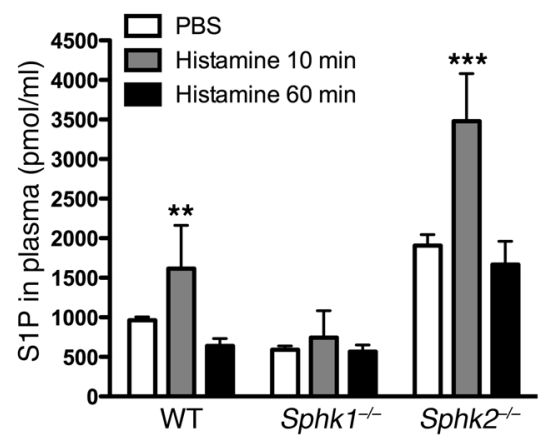

B

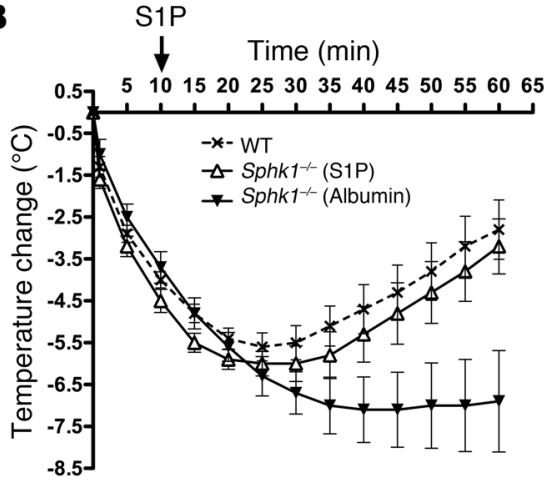

C

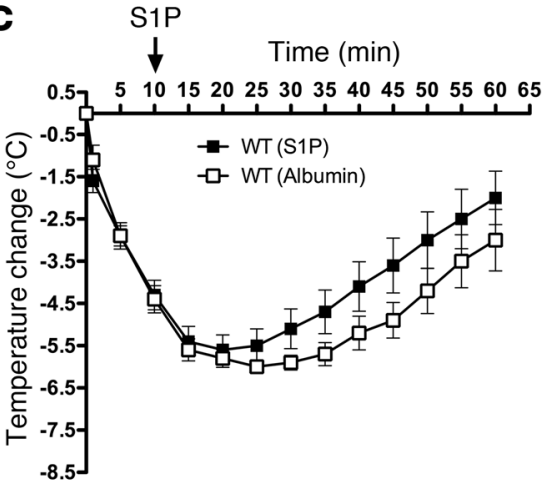

Figure 3

Histamine induces SphK1-dependent increases in plasma S1P levels, and an acute administration of S1P increases the rate of recovery from

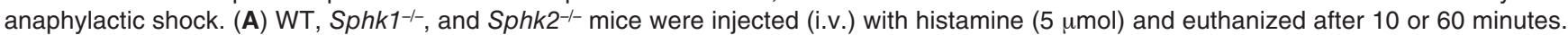
Blood was extracted by cardiac puncture and S1P levels were determined. ${ }^{* *} P<0.01,{ }^{* *} P<0.001$, determined by Student's $t$ test. (B and C) Anaphylaxis was induced in Sphk $1^{-/-}$mice or WT mice by histamine $(5 \mu \mathrm{mol})$, and after 10 minutes, $500 \mu \mathrm{M}$ S1P or vehicle (mouse albumin in saline) was administered (i.v.). Body temperature measurements were as described in Methods. (Sphk1/-- [albumin], $n=8 ;$ Sphk1-/- [S1P], $n=7$; WT [albumin], $n=5$; WT [S1P], $n=7$ ).

and initiate a feedback regulatory loop that counteracts anaphylaxis. We reasoned that if this activation occurs in the vascular system or its vicinity, an acute increase of S1P should be detected in the circulation. As shown in Figure 3A, histamine induced an increase

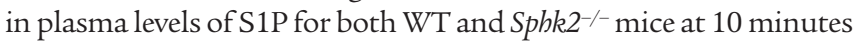
after challenge, but no increase was observed in Sphk1-1- mice. The acute increase (S1P levels returned to baseline by 60 minutes) was

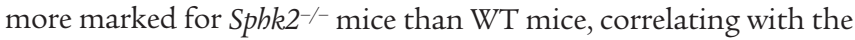
more rapid recovery of the former genotype (Figure 1B). To determine whether an acute increase in S1P had a role in the recovery

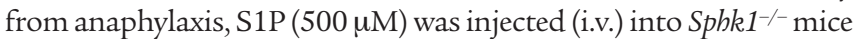
10 minutes after the induction of anaphylaxis, and the response was compared with mice injected with vehicle alone. As shown in Figure 3B, S1P injection rescued Sphk1 $1^{-/-}$mice from anaphylaxis, mimicking the recovery seen in WT mice, suggesting that an acute increase in S1P can bypass the need for SphK1. Injection of S1P in WT mice also showed a modest improvement in the rate of body temperature recovery, although not to the same extent as $S p h k 1^{-/-}$mice (Figure $3 \mathrm{C})$. Collectively, these results demonstrate that histamine induces an acute increase in SphK1 activity to produce S1P, which in turn is associated with recovery from anaphylaxis.

The S1P receptor S1PR2 is needed for recovery from anaphylaxis. S1P receptor family members are important for the regulation of the vascular system. Of the $5 \mathrm{~S} 1 \mathrm{P}$ receptors, S1PR1-S1PR3 were the most likely candidates to regulate anaphylaxis, because of their abundance in vasculature, a key target of histamine function (30, 31 ), and their recognized roles in vascular function $(12,18,32$, $33)$. To determine their relative contributions, we induced anaphylaxis in mice genetically deficient in S1PR2, S1PR3, and S1PR4 receptors and also in mice carrying an inducible deletion ( $\mathrm{Mx}$-Cre recombinase) of floxed S1pr1 alleles (34), since targeted disruption of this gene causes embryonic lethality. Induction of Cre recombinase activity in $S 1$ pr $1^{10 x P / l o x P-M x}$ mice resulted in a $70 \%-90 \%$ reduction in the S1pr1 mRNA in the aorta, heart, kidneys, and spleen and a $40 \%$ reduction in lung (Supplemental Figure 3). As shown in Figure 4A, anaphylaxis of S1PR1-deficient mice did not differ from that of WT mice, suggesting that a marked reduction in the levels of S1PR1 did not alter recovery from anaphylaxis. In contrast, the lack of S1PR2 expression had a dramatic effect on the duration of histamine-induced anaphylaxis (Figure 4B) as well as IgE/Ag-induced anaphylaxis (data not shown). Genetic deletion of S1PR3 and S1PR4 had no significant effect on histamineinduced anaphylaxis (Figure 4, C and D). Unlike Sphk1 $1^{-1-}$ mice (Figure 3B), S1pr2 $2^{-/-}$mice were not responsive to acute administration of S1P (Figure 5A), indicating that in Sphk $1^{-/-}$mice the rescue from anaphylaxis by S1P was likely mediated through S1PR2. To further test this possibility, we investigated whether a single allele of S1PR2 would allow recovery from anaphylaxis. As shown in Figure 5B, a trend toward partial recovery of body temperature was observed, and this was markedly enhanced when S1P was administered, underscoring the importance of this receptor in the recovery from anaphylaxis.

Vascular permeability changes in Sphk1-/- and S1pr2-/- mice play a minor role or do not account, respectively, for the poor recovery from anaphylaxis. Since differences in vascular permeability, relative to WT mice, could also contribute to the poor recovery from anaphylaxis, we explored the changes in vascular permeability in models of systemic and local challenge (Supplemental Figure 4). Measurement of vascular permeability in the peritoneum and the lung did not reveal any significant differences among the respective WT,

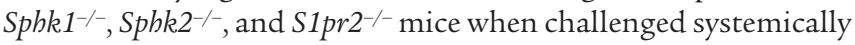
with IgE/Ag (Supplemental Figure 4A). However, both a systemic and local histamine challenge showed, respectively, increased vascular permeability (hematocrit measurement) and enhanced local

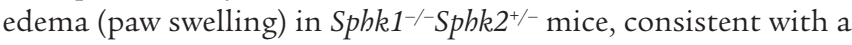
previous report in mice deficient in both kinases (12). A modest trend toward increased vascular permeability (not statistically

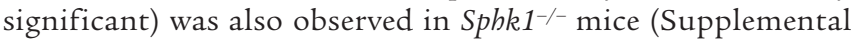
Figure 4, B-D). In contrast, for S1pr2-/- mice the hematocrit did not increase during histamine-induced anaphylaxis and edema appeared to be reduced (albeit not significantly relative to WT mice). This demonstrates that poor recovery from anaphylaxis of $S 1 \mathrm{pr}^{-{ }^{--}}$mice is not linked to increased vascular permeability. Local challenge with compound 48/80 (a potent stimulus of 
A

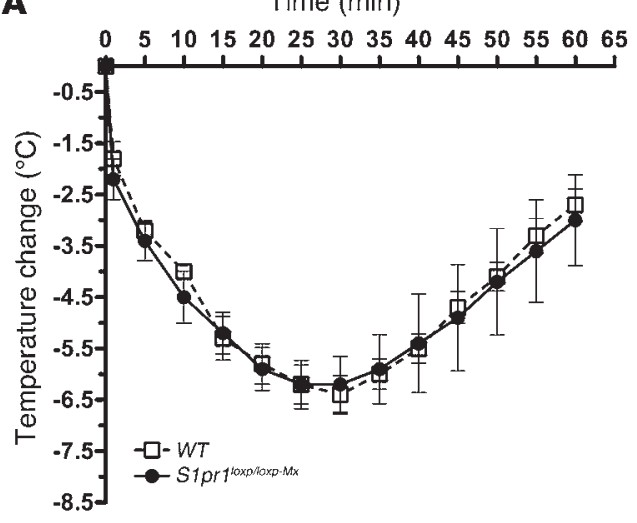

C

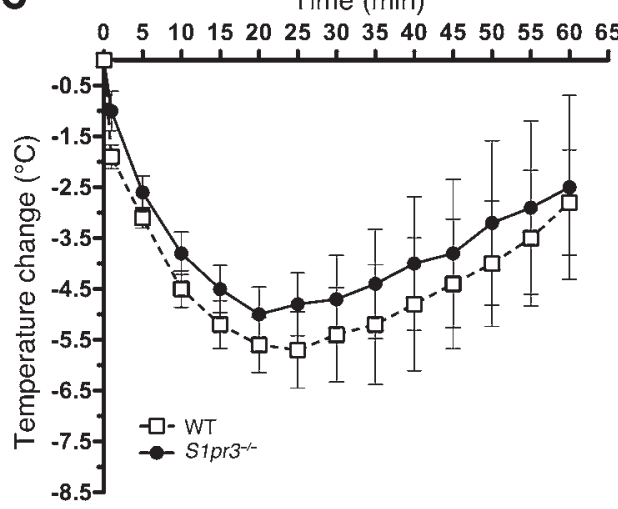

B

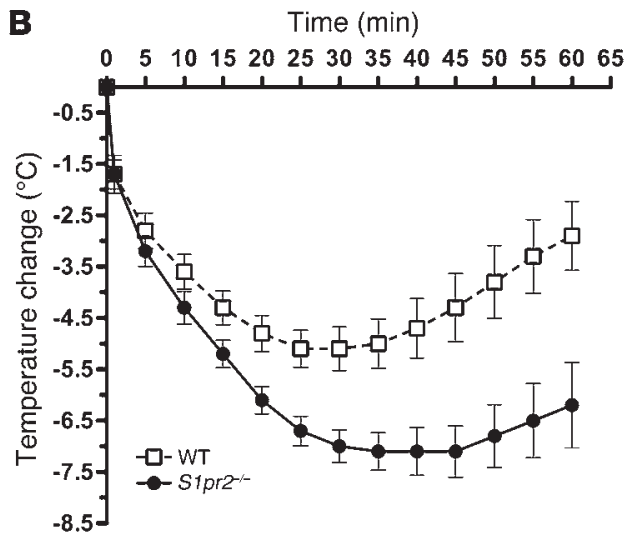

D

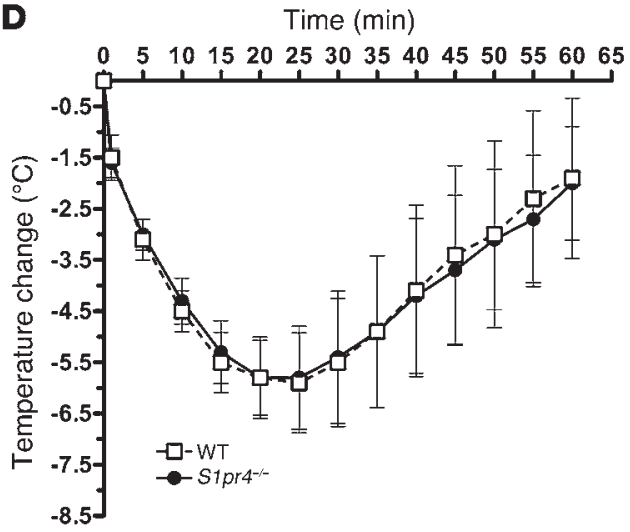

Figure 4

The S1PR2 receptor controls the duration of anaphylaxis. (A) S1pr1loxp/loxp-Mx $(n=4),(B)$ S1pr2 ${ }^{-/-}(n=8)$, (C) S1pr3 ${ }^{--}$ $(n=4)$, and (D) S1pr4 ${ }^{-/-}(n=4)$ mice and their respective WT counterparts were subjected to anaphylaxis induced by histamine $(5 \mu \mathrm{mol})$. The WT counterpart for S1pr1/oxp/loxp-Mx mice are S1pr1loxp/loxp mice, as described in Methods. Body temperature measurements were performed as described in Methods. mast cell degranulation) again revealed a trend (albeit not sig-

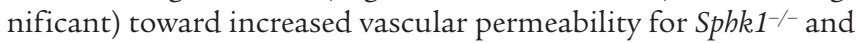

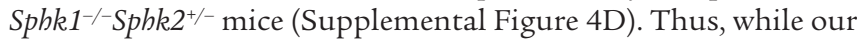
findings demonstrate a modest increase in vascular permeability

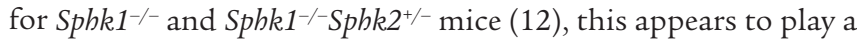

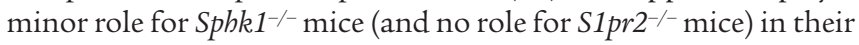
poor recovery from anaphylaxis.

SphK1 and S1PR2 contribute to renal histamine clearance. Considering that S1PR2 has been involved in the general maintenance of vascular tone and renal vascular resistance (33) and that the kidney is the key organ for the disposal of histamine from the circulation (35-37), one might hypothesize that a reduction of renal

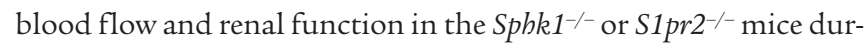
ing anaphylaxis could impair their ability to clear histamine and thus recover from shock. To assess whether this was a possibility, the plasma levels of unmodified, biologically active histamine were

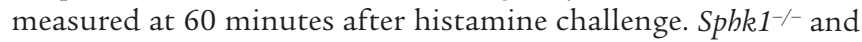
S1pr2 $2^{-/-}$mice had higher levels of circulating histamine when compared with their respective WT littermates (Figure 6A). In contrast, Sphk2-/- mice had lower levels of histamine remaining in circulation (Figure 6A, left), correlating with the faster recovery of Sphk2-/mice from anaphylaxis. Similar results were obtained in mice in which anaphylaxis was induced by IgE/Ag (data not shown). S1P administration to $S p h k 1^{-/-}$mice, which rescued these mice from
Figure 5

Administration of S1P does not increase the rate of recovery from anaphylaxis for S1 pr2 $2^{--}$mice. (A) S1pr2-/- and (B) S1pr2+/- mice were subjected to anaphylaxis by histamine injection $(5 \mu \mathrm{mol})$. Ten minutes after the histamine bolus, $500 \mu \mathrm{M}$ S1P or vehicle were administered, and body temperature was monitored as described in Methods. $n \geq 8$ in all groups.
$\mathbf{A}$

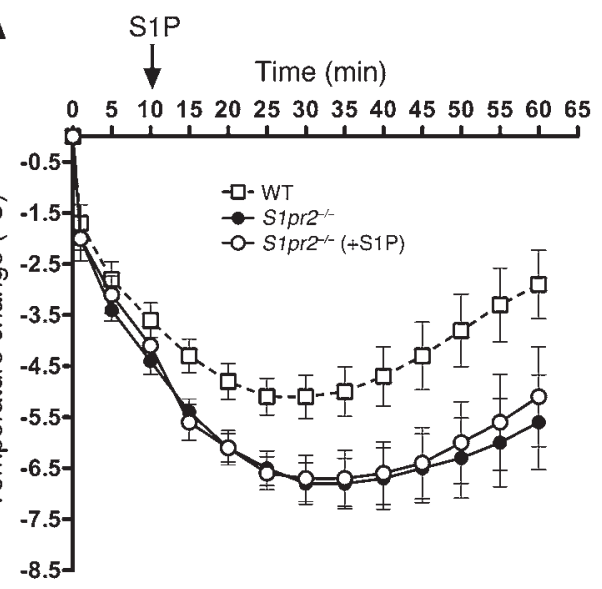

B $\quad S_{1 P}$

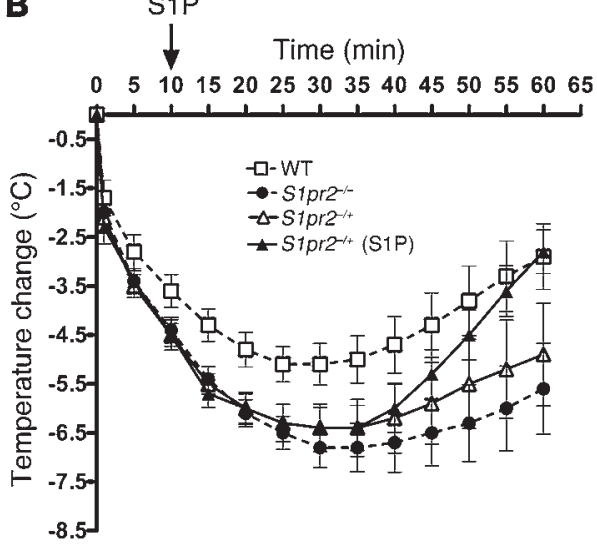



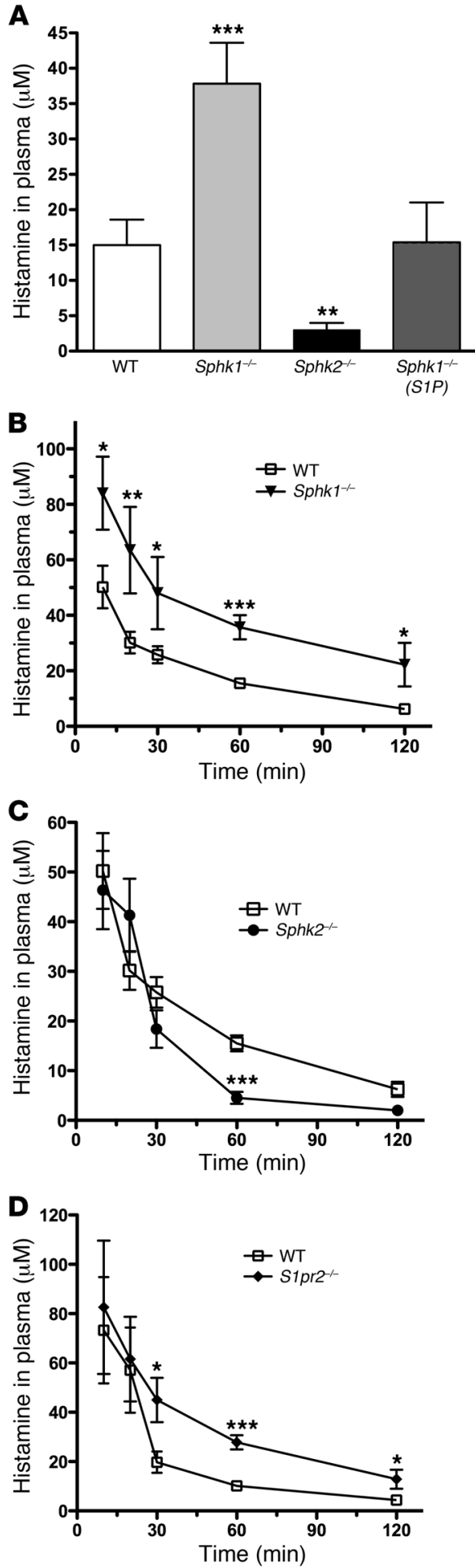
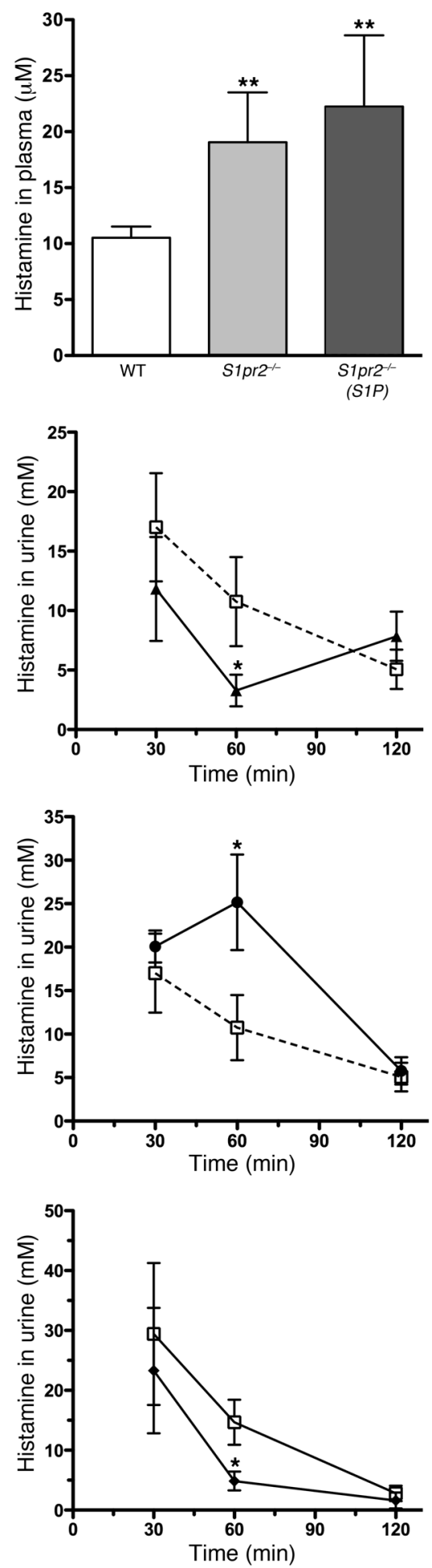

Figure 6

Clearance of plasma histamine and excretion are impaired in Sphk1-/- and S1pr2-/- mice but enhanced in Sphk2-/- mice. (A) Histamine $(5 \mu \mathrm{mol})$ was injected into the indicated mice, and after 60 minutes, mice were euthanized and blood was drawn. As indicated, $500 \mu \mathrm{M}$ S1P was administered to some mice 10 minutes after induction of anaphylaxis. Plasma histamine levels were determined for all genotypes and treatments as indicated. (B-D) Kinetics of plasma histamine clearance (left panels) and its appearance in urine (right panels) for (B) Sphk $1^{-1-}$, (C) Sphk2-/- and (D) S1pr2-/- mice and their corresponding WT counterparts $(n=4-7)$. Blood was drawn $(\sim 2 \mu \mathrm{l})$ from each mouse from the tail vein at the indicated times. Urine was collected (when possible) at the indicated times. Histamine was measured by competitive ELISA. ${ }^{*} P<0.05,{ }^{* \star} P<0.01,{ }^{* \star *} P<0.001$, determined by Student's $t$ test.

thus recovery from anaphylactic shock. If the defective elimination of histamine in $S p h k 1^{-/-}$ and S1pr2-/- mice were due to impaired catabolism of histamine, this would be reflected by an increase in unmodified histamine in both plasma and urine. However, the kinetics for the disappearance of unmodified histamine from plasma (Figure $6, \mathrm{~B}$ and $\mathrm{D}, \mathrm{left}$ ) and its appearance in the urine (Figure 6, B and D, right) showed that the delayed clearance of plasma histamine

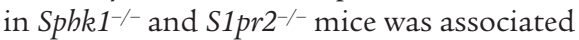
with decreased excretion of histamine. In contrast, clearance of histamine was more efficient in Sphk2 $2^{-/}$mice, and this was associated with increased excretion (Figure 6C, left and right). Thus, the inability of Sphk1-/and S1pr2-/- mice to clear unmodified histamine during anaphylaxis suggests a failure in the renal excretion of histamine and not in the catabolism of histamine. However, for Sphk2-/- mice, we cannot exclude that both increased catabolism and excretion of histamine might account for the efficient clearance of histamine from the plasma.

The SphK1/S1P/S1PR2 axis counteracts bypotension during anaphylaxis. During anaphylactic shock, arterial blood pressure and/or local regulation of renal blood flow can be profoundly compromised, impairing glomerular filtration and thus renal excretion. To test this possibility, we monitored the blood pressure

the prolonged anaphylaxis (Figure 3B), also reduced the levels of plasma histamine to the levels found in WT mice (Figure 6A, left). To test whether the clearance of histamine depended on S1P receptors, $\mathrm{S} 1 \mathrm{P}$ was administered as above to $\mathrm{S} 1 \mathrm{pr} \mathrm{2}^{-/-}$mice, but no reduction in plasma histamine was observed (Figure 6A, right). This is consistent with the view that activation of S1PR2 receptors by $\mathrm{S} 1 \mathrm{P}$ during anaphylaxis facilitates the disposal of histamine and of isoflurane-anesthetized mice during histamine-induced anaphylaxis. Baseline blood pressure measured over a 10 -minute period in

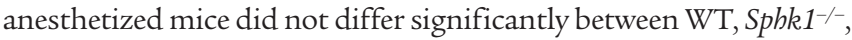

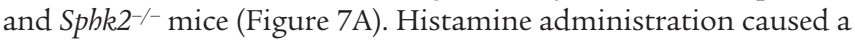

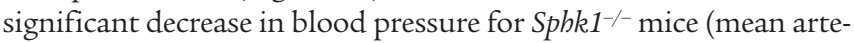
rial blood pressure [ $\triangle \mathrm{MAP}$ ], $45 \pm 5 \mathrm{mmHg}$ ) as compared with WT mice $(\triangle \mathrm{MAP}, 32 \pm 3 \mathrm{mmHg}$ ). In contrast, the drop in blood pressure 
A
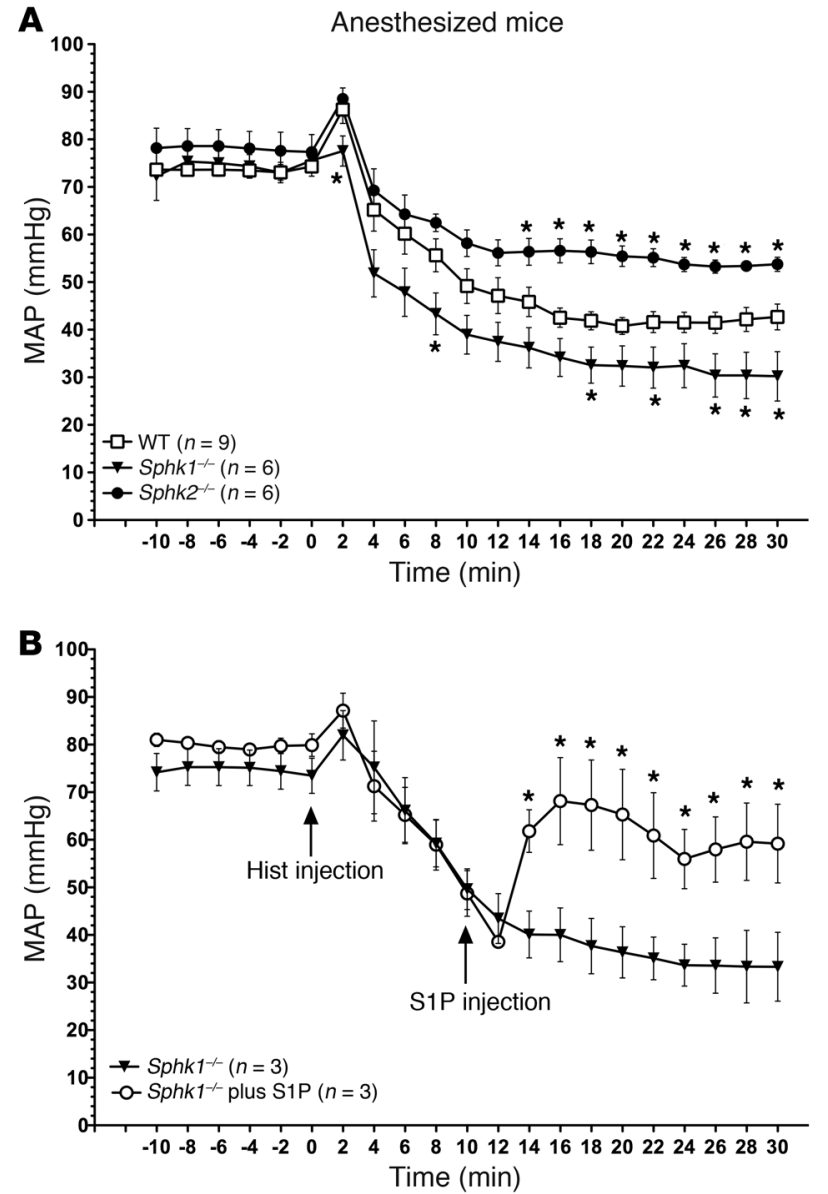

C

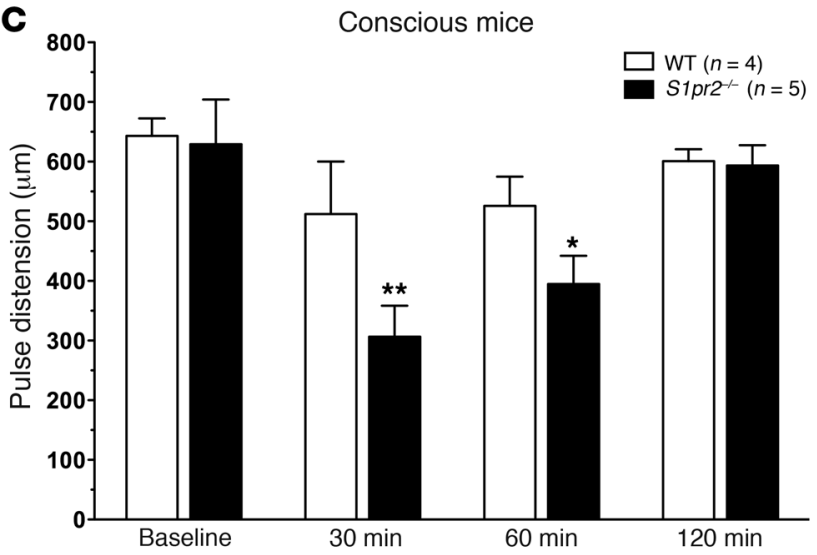

D

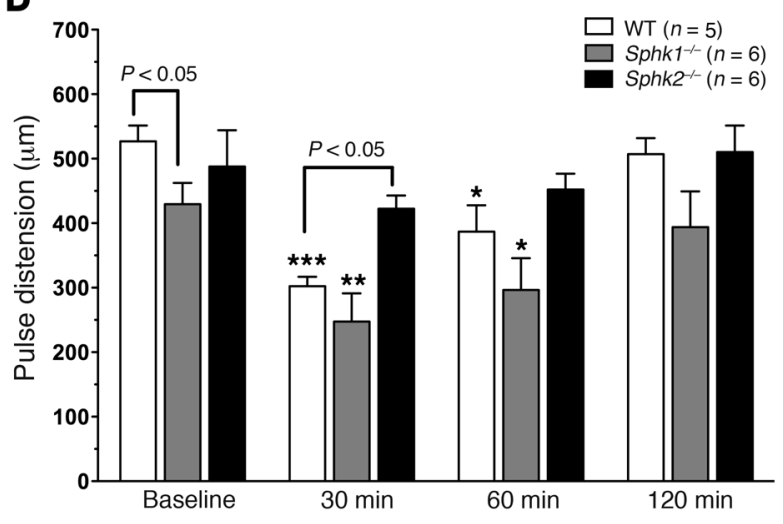

Figure 7

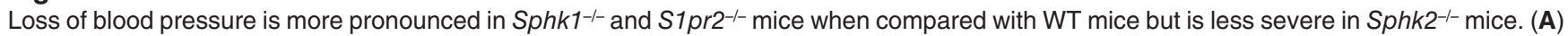
MAP before (10 minutes) and after (30 minutes) histamine injection ( $5 \mu \mathrm{mol}$; at time 0$)$ in isoflurane-anesthetized WT $(n=9)$, Sphk1-/- $(n=6)$, and Sphk2-l- mice $(n=6)$. Graph lines connect mean values of MAP at 2-minute intervals. ${ }^{*} P<0.05$, between WT and Sphk ${ }^{-1-}$ mice, determined by Student's $t$ test. (B) MAP of anesthetized Sphk $1^{-1-}$ mice after histamine injection alone or in combination with S1P treatment (10 minutes after histamine bolus as indicated). The effect of S1P on MAP in the WT mice under anaphylaxis was about half of that seen in the Sphk1-/- mice (data not shown). (C and D) Blood flow in conscious mice determined by pulse distension measurements in (D) WT $(n=6), \operatorname{Sphk1/-}(n=6)$, and Sphk2 $2^{--}(n=6)$ mice or (C) S1pr2 ${ }^{-/-}(n=6)$ and their WT $\left(S 1 p r 2^{+/+}\right)$counterparts $(n=4)$ at baseline and at 30, 60, and 120 minutes after histamine bolus. ${ }^{\star} P<0.05$, ${ }^{\star \star} P<0.01$, ${ }^{\star \star *} P<0.001$, compared with baseline, determined by a Student's $t$ test.

of Sphk2-/- mice was not as pronounced ( $\triangle \mathrm{MAP}, 24 \pm 3 \mathrm{mmHg}$ ), consistent with their ability to more effectively clear plasma histamine and increase its excretion in the urine. The effect of histamine on the measured blood pressure over the 30-minute observation period (integrated AUC) showed a significant lowering in the blood pressure of Sphk1 $1^{-/}$mice (AUC, $1221 \pm 124 \mathrm{mmHg} \times$ min; $P<0.05$ ) relative to that of WT mice (AUC, 1,520 $\pm 74 \mathrm{mmHg} \times$ min), whereas a significantly higher blood pressure was observed in Sphk2-/- mice (AUC, $1,810 \pm 69 \mathrm{mmHg} \times \min ; P<0.05$ ). To examine whether the

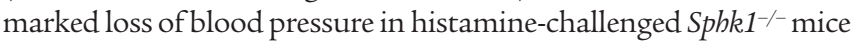
resulted from the lack of S1P production during anaphylaxis, exogenous S1P was administered 10 minutes after the histamine bolus. Administration of S1P during anaphylaxis caused a rapid increase

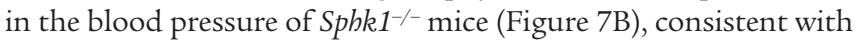
the observed effect of S1P in promoting the clearance of histamine from plasma of these mice (Figure 6A) and the recovery of body temperature (Figure 3B). Accordingly, the GFR after the injection of histamine was reduced in Sphk1/-- mice $(97 \pm 41 \mu \mathrm{l} / \mathrm{min} ; n=6)$ but was restored after S1P injection (171 $\pm 52 \mu \mathrm{l} / \mathrm{min} ; n=3)$, similar to that of WT mice $(180 \pm 31 \mu \mathrm{l} / \mathrm{min} ; n=6)$ (Supplemental Figure 5). It is important to note that GFR measurements during the anaphylaxis of $S p h k 1^{-/-}$mice, when an increase in vascular leakage relative to WT mice may be observed (Supplemental Figure 4), could be overestimated due to the escape of inulin (used to measure GFR) from blood into the extravascular space.

Analysis of blood pressure after induction of anaphylaxis in anesthetized S1pr2-/- mice revealed no difference relative to their WT littermates (Supplemental Figure 6). Only limited GFR measurements could be conducted due to a precipitous drop in the blood pressure of both WT and S1pr2-/- anesthetized mice. The rates observed for WT mice $(\sim 17 \mu \mathrm{l} / \mathrm{min})$ and S1pr2 $2^{--}$mice $(\sim 11$ $\mu \mathrm{l} / \mathrm{min}$ ) were approximately similar (numbers represent the mean of $n=5$ mice, with 3 mice in each group showing no measurable GFR). This was unexpected since S1pr2 ${ }^{-/-}$mice, but not their WT counterparts, were impaired in the clearance of plasma histamine and its excretion (Figure 6, A and D). We hypothesized that the loss 


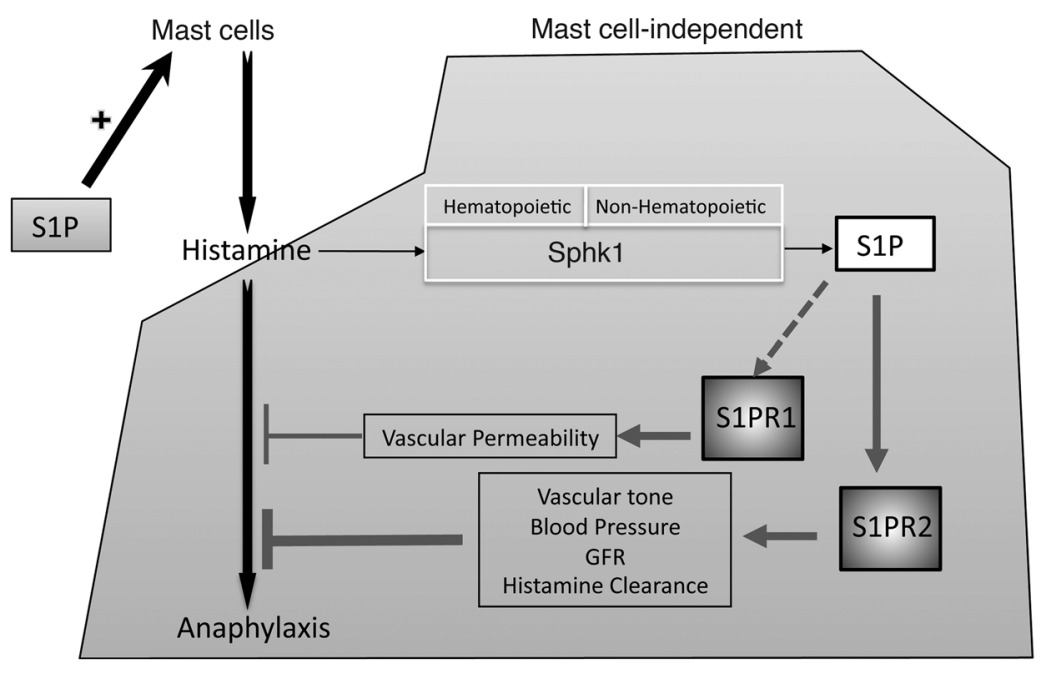

Figure 8

Proposed model for the dual actions of S1P in the onset of and recovery from anaphylaxis. While S1P appears to enhance signaling and function of mast cells, which are initiators of the allergic response, it alleviates the symptoms of the anaphylactic shock, acting in a mast cell-independent manner. Histamine released from mast cells activates SphK1 to produce S1P. Although SphK1 in the hematopoietic compartment contributes to the recovery from anaphylaxis, SphK1 in a nonhematopoietic compartment is essential for this function. S1P produced by SphK1 activates S1PR2 receptors, which aid in the clearance of histamine to terminate anaphylaxis. The increased clearance of histamine mediated by S1PR2 appears to be hemodynamic in nature, i.e., a consequence of its regulation of vascular tone and thus blood pressure, which in turn can control GFR. SphK1 and S1P production can also activate S1PR1 receptors, which prevent vascular leakage, and this may contribute to recovery, although in the model of anaphylaxis used herein, the involvement of S1PR1 appears to be modest compared with that of S1PR2.

of S1PR2 receptor in the vasculature might cause a difference in the effects of anesthesia that masked potential differences in blood pressure during anaphylaxis. Thus, we used a pulse oximeter in conscious mice to measure pulse distension, an indicator of blood flow and thus blood pressure, during anaphylaxis. A significant difference in the pulse distension of S1 $\mathrm{pr}^{-/-}$mice was found at 30 and 60 minutes after histamine challenge (Figure 7C), consistent with a more severe and longer lasting anaphylactic response in S1pr2-/- mice (Figures 4 and 5). To validate that pulse oximetry was consistent with the measurement of blood pressure in anesthetized

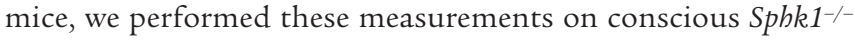
and Sphk2-1- mice as well as their WT counterparts. Baseline measurements in WT $\left(S p h k^{+/+}\right)$mice differed slightly from those of WT $\left(S 1\right.$ pr $\left.^{+/+}\right)$mice, probably due to differences in the genetic background. As shown in Figure 7D, pulse distension measurements in these conscious mice provided similar results as the blood pressure measurements in the anesthetized mice. The decrease in pulse distension after histamine injection was more pronounced and longer lasting in the Sphk1-/- mice, with a minimal change for the Sphk2-/- mice. This showed that the anesthesia was likely responsible for the failure to see differences in the blood pressure of the anesthetized S1pr2-/- mice versus corresponding WT mice. Measurement of changes in the heart rate and respiration of conscious mice, which are hallmarks of anaphylaxis, showed a pronounced drop in the heart and breathing rate of $S 1 \mathrm{pr}^{-{ }^{--}}$mice relative to WT mice after 30 minutes (Supplemental Figure 7). Arterial oxy- gen saturation was not altered, remaining at greater than $97 \%$ in all mice, despite a reduced breathing rate (data not shown). Collectively, the findings argue that the major mode by which both SphK1 and S1PR2 control the recovery from histamineinduced anaphylaxis is through the regulation of blood pressure and probably the GFR and thus the clearance of histamine from the circulation.

\section{Discussion}

In its most severe form, anaphylaxis is characterized by bronchospasm, upper respiratory angioedema, and/or hypotension. Massive vasodilation, fluid extravasation, and repressed myocardial function can result in death (1-3). Here, we demonstrate that the SphK1-S1PR2 axis regulates anaphylaxis-induced hypotension, the elimination of histamine from the circulation, and the duration of anaphylactic shock.

It is generally agreed that mast cells play a central role in the onset of many anaphylactic episodes by recognizing the presence of an allergen through allergen-specific IgE antibodies bound to the cell surface receptor, FceRI. Engagement of FceRI causes the release of potent allergic mediators, like histamine, from mast cell granules. The activation of mast cells is also intimately linked with the induction of SphK1 and SphK2 activity in mast cells $(13,14,16,38)$ and with the production and secretion of $\operatorname{S1P}(13,38)$. Studies in embryonic liver-derived mast cells or in

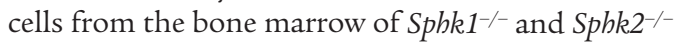
neonates (prior to detecting any influence by varied levels of circulating S1P) showed that SphK2 is the main isoenzyme involved in the production of S1P and found that this isoenzyme is important for mast cell responses, whereas SphK1 did not appear to play a major role in the response of these cells (15). In contrast, differences in plasma S1P levels of adult $S p h k 1^{-/-}$(low amount) versus $S p h k 2^{-\gamma^{-}}$(high amount) mice, relative to WT mice, were demonstrated to change the in vivo

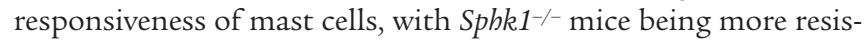
tant to anaphylaxis than Sphk2-/- mice (15). Here, we found that the amount of histamine released from mast cells upon anaphylactic challenge was associated with the loss of body temperature within the first 10 minutes of anaphylaxis (Figure 1A). However, after 15 minutes, the recovery from anaphylaxis (as measured by increasing body temperature) was rapid for Sphk $2^{-/-}$mice and delayed in Sphk1 $1^{-1-}$ mice, relative to WT littermates (Figure 1A). The recovery was mast cell-independent (Figure 1B) but was associated with the amount of circulating histamine and with the relative contribution of the SphK-S1PR gene products in clearing plasma histamine (Figure 6) during the hypotension induced by anaphylaxis.

Histamine is responsible for some of the major symptoms associated with systemic anaphylaxis, as shown in a murine model of histamine deficiency upon genetic deletion of the histidine decarboxylase $(H D C)$ gene (21). $H d c^{-/}$mice showed no significant alterations in body temperature or in respiration during Ag-mediated anaphylaxis, but a histamine challenge led to a marked loss of body temperature, demonstrating the role of histamine in regulating body temperature. In agreement, we found that histamine decreased body temperature, decreased blood pressure (Figure 7), 
and caused changes in the heart rate and respiration (Supplemental Figure 7). Moreover, a histamine challenge of $S p h k 1^{-/-}$or $S 1 p r 2^{-/-}$ mice (which exhibited the most severe anaphylactic response) resulted in the death of only $1 \%-2 \%$ of the mice.This is consistent with the frequency of death reported by the American College of Allergy, Asthma and Immunology Epidemiology of Anaphylaxis Working Group (39), emphasizing the physiological relevance of the model used herein.

Under normal conditions, secreted histamine is rapidly bound to its receptors or can be inactivated by oxidative deamination or methylation $(36,37)$. Nonetheless, a considerable amount of histamine is still excreted unmodified $(35,37)$, and in humans, cases of histamine intolerance due to ingestion of spoiled fish (40) or other amine-rich foods (41), endogenous histamine overproduction, or an imbalance between the accumulation of histamine and its elimination are known to result in elevated plasma histamine levels and severe allergic reactions (41) or recurrent anaphylaxis (42). This suggests that histamine exceeds its physiological usefulness during exposure to large amounts of it, and this overwhelms the inactivation mechanisms, causing unwanted effects on blood pressure, vascular tone, and permeability. In addition, there may be differences in the responses of individuals to histamine, based in part on the physiological effects mediated by the 4 known histamine receptors $\left(\mathrm{H}_{1-4}\right)$, which differ in tissue distribution and affinity for histamine $(43,44)$. Polymorphisms discovered in histamine receptors may also account for some of the physiological differences $(45,46)$. It is well known that histamine increases endothelial permeability $(47,48)$. The recent finding that histamine also increases SphK1 expression and activity in human arterial endothelial cells (29) provides evidence of an additional mode by which histamine might modulate the vasculature. Here, we found that histamine increased the levels of S1P in an SphK1-dependent manner (Figure 4A), and this is important for blood pressure recovery during anaphylaxis. In agreement, alterations of S1P levels by overexpression of SphK1 in resistance arteries increased the resting tone of these arteries (49), which are thought to regulate blood pressure and tissue perfusion, and mediated transmural pressure-induced reactive oxygen species formation and myogenic reactivity (50). Degradation of SphK1-produced S1P by overexpression of a S1P phosphatase (S1P phosphohydrolase 1) results in the negative regulation of resting and myogenic tone in resistance arteries, indicating a role for S1P (derived from SphK1 activity) in the contractility of these arteries (51) and thus in the regulation of blood pressure. Our data provide what we believe to be new insights into an additional mechanism that may contribute to the differences in sensitivity of individuals to histamine or in cases of histamine intolerance.

The receptors for S1P, particularly S1PR1, S1PR2, and S1PR3 are abundant and widely distributed in the vascular system, in which they have important roles in the contractility and permeability of the vasculature $(18-20,52)$. In endothelial cells, S1PR1 preserves vascular integrity and regulates vascular permeability $(12,20,53)$; S1PR3 appears to function in myocardial contractility and regulation of bradycardia and hypertension induced by S1P (32); and S1PR2 increases vascular permeability and regulates renal, mesenteric, and local blood flow in various organs $(20,54,55)$. Here, we show that in a model of non-lethal anaphylaxis, S1PR2 played an important role, counteracting the vasodilatory actions of histamine, while the other receptors for S1P seemed to be dispensable (Figures 5-8). This is consistent with prior studies $(51,56)$ that suggest a role for $\mathrm{S} 1 \mathrm{PR} 2$ in the vasoconstriction induced by $\mathrm{S} 1 \mathrm{P}$ in resistance and coronary arteries. Additional studies in S1pr2 ${ }^{-/-}$mice showed a decreased contractile responsiveness and vascular tone in vivo, suggesting a role for S1PR2 in the maintenance of vascular hemodynamics (54). We did not observe differences in the blood pressure or body temperature of $S 1 \mathrm{pr}^{-/-}$versus WT mice in the absence of a challenge, but a marked difference was observed during the hypotension induced by anaphylaxis (Figures 4 and 7). This demonstrates that the S1PR2 receptor is particularly important in response to acute vascular vasodilatory influences. The marked hypotension of these mice during anaphylaxis correlates with their inability to properly clear histamine, suggesting that the defective renal function may derive from a compromised GFR, although a direct function of this receptor on the kidney cannot be excluded.

However, histamine- or platelet-activating factor-induced ana-

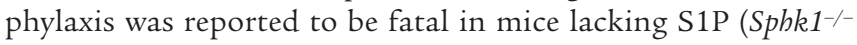
Sphk2 $2^{-1-}$ mice) (12), and this lethality was attributed to a lack of signaling through the S1PR1 receptor, since administration of a selective agonist of S1PR1 (AUY954) to these mice without S1P increased survival. The S1PR1 receptor would function to regulate vascular permeability during anaphylaxis, preventing the extensive vascular fluid extravasation that can cause lethality. We found that injection of histamine in the footpad of the S1PR1 inducible knockdown mice (S1pr1 $1^{\text {loxp/loxp-Mx }}$ mice), which had a reduced presence of S1pr1 in tissues (Supplemental Figure 3) and in the endothelium of the aorta (Supplemental Figure 8E), induced a temporal enhancement in local swelling (Supplemental Figure $8 \mathrm{C}$ ), confirming the involvement of this receptor in vascular permeability. In contrast, S1PR1 deficiency did not alter the rate of recovery from histamine-induced anaphylaxis (Figure 4), although a trend for elevated hematocrit and accumulation of Evans Blue in their lungs (albeit not significant) was seen after IgE/Ag challenge (Supplemental Figure 8, A and B). Furthermore, inhibition of S1PR1 receptors by VPC23019 (57) (Supplemental Figure 8, F and $\mathrm{G}$ ) did not result in lethality or the worsening of anaphylaxis

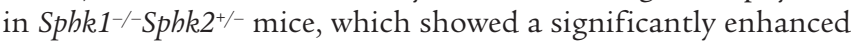
vascular permeability (Supplemental Figure 4), while it modestly increased the intensity of the shock in the Sphk2-/- mice, which did not show significant vascular leakage during anaphylaxis as determined by hematocrit changes (Supplemental Figure 4). Thus, altogether our data suggest a modest involvement of S1PR1 and vascular permeability in this non-lethal model of histamineinduced anaphylaxis (see model in Figure 8). However, we recognize the possibility that some S1PR1 may remain in the S1pr $1^{\text {loxp/loxp-Mx }}$ mice and may be sufficient to regulate microvascular permeability and prevent worsening of the disease. Similarly, poor recov-

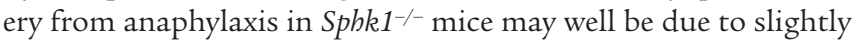
higher plasma exudation in these mice (Supplemental Figure 4), which can also contribute to the hypotension. Regardless, our findings demonstrate that the activation of S1PR2 and its role in blood pressure regulation during anaphylaxis is dominant over the role of S1PR1 in controlling vascular permeability (see model in Figure 8) (under conditions in which S1P is present in the circulation), because $S 1 \mathrm{pr}^{-/-}$mice suffer a severe anaphylaxis (despite an apparent reduction in plasma exudation relative to WT mice; Supplemental Figure 4) that cannot be reversed by S1P injection. Further support is also provided by the finding that antagonism of S1PR1 did not worsen anaphylaxis in S1pr2 $2^{-/-}$mice, and S1pr2-/S1pr $1^{\text {loxp/loxp-Mx }}$ double-deficient mice did not exhibit lethality or a more severe anaphylactic response when compared with S1pr2-/mice (Supplemental Figure 8, H and I). The data shown herein and 
the findings by Camerer et al. (12) in the mice without S1P, using a more severe model of anaphylaxis, are not inconsistent, since cooperation between S1PR1 and S1PR2 has been shown to regulate microvascular permeability $(20,52)$. Moreover, our findings and those of Camerer et al. demonstrate the importance of S1P in recovery from anaphylactic shock, whether in the circulation (12) or in the local environment of the vasculature.

Our findings argue for a feedback regulatory mechanism that is important in recovery from anaphylaxis; it involves the histaminedependent stimulation of SphK1 in both the hematopoietic and nonhematopoietic compartments, the production of S1P, and the activation of S1PR2, which controls vascular tone and facilitates recovery of blood pressure and clearance of histamine (see model in Figure 8). In fact, administration of S1P after the initiation of shock improved the recovery from anaphylaxis in WT mice (Figure 3C) to a similar extent as adrenaline (data not shown). While adrenaline is the recommended first-line treatment in anaphylaxis $(22,23)$, the administration of adrenaline carries risks, particularly in the elderly population, that include cardiac arrhythmias, myocardial infarction, and hypertensive intracerebral bleeds $(5,22)$. Therefore, adrenaline overdosing in non-life-threatening allergic reactions is a serious risk. Since the S1PR2 receptor does not mediate bradycardia, tachycardia, or influence myocardial function in vivo and its effects on blood pressure and flow rate appear to be mostly vascular (54), specific receptor agonists may be a safer and useful alternative for anaphylaxis treatment in the high-risk population. This would need to be balanced with the possibility of increased lung vascular permeability by engagement of S1PR2 receptors (55). Vascular permeability in the lung could be counteracted by administration of S1P or engagement of S1PR1 receptors in the lung (58). In light of our findings and the recent report from Camerer et al. (12), a combination treatment with specific agonists to S1PR1 and S1PR2 receptors could be particularly effective for the reversal of vascular leakage and hypotension, respectively, during anaphylaxis.

\section{Methods}

Mice. Mice were maintained and used in accordance with NIH guidelines and animal study proposals approved by the NIAMS or the NIDDK animal

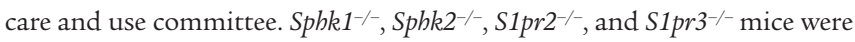
generated as previously described $(15,27,52,59,60)$. S1 $\mathrm{pr}^{-/-}$mice were obtained from The Jackson Laboratory (stock no. 005799), and the respective $S p h k 1^{+/+}, S p h k 2^{+/+}, S 1 p r 2^{+/+}, S 1 p r 3^{+/+}$, and $S 1 p r 4^{+/+}$mice (referred to as WT mice) were obtained from heterozygous mating pairs. Genotyping was performed as described previously $(15,34,59,60)$. Mice carrying an inducible deleted (Mx-cre) S1P gene (S1pr1 loxp/loxp-Mx mice) on the C57BL/6 background (N10) were generated as described previously (34). S1 1 r $1^{\text {loxp } / \text { loxp }-M x}$ mice and the respective control mice (S1priloxp/loxp $)$ were injected intraperitoneally with polyinosinic-polycytidylic acid ( $\mathrm{pIpC} ; 250 \mu \mathrm{g}$ per injection) 3 times at 2-day intervals. Mice were analyzed at 4 weeks after the first $\mathrm{pIpC}$ injection. To determine the level of expression of the S1PR1 receptor after PIpC injection, its transcript was measured by quantitative real-time PCR (TaqMan Gene Expression Assays; Applied Biosystems) from various organs of the S1pr $1^{10 x p / l o x p-M x}$ mice and S1pr $1^{\text {loxp/loxp }}$ mice. Mast cell-deficient mice $\left(W^{S b} / W^{S b}\right.$ mice, C57BL/6; The Jackson Laboratory) and WT littermates were generated in-house from heterozygous matings.

Irradiation and bone marrow transplantation. Bone marrow cells were isolated from the femurs and tibias of WT or Sphk $1^{-/-}$mice. After removing $\mathrm{rbc}$, a single-cell suspension $\left(2-3 \times 10^{6}\right.$ cells/mouse $)$, in $0.2 \mathrm{ml}$ of saline, was injected into the tail veins of lethally irradiated (9 Gy) WT or Sphk1-/mice. The recipient mice were maintained in a sterile environment with acidified water for at least 8 weeks before they were subjected to histamine-induced anaphylaxis. Seven to fourteen days after recovery from the anaphylactic shock, the mice were euthanized, blood was drawn for S1P measurements, and genotyping of the mice and peripheral blood cells was performed to confirm successful engraftment and to verify the identity of donor and recipient mouse.

Anaphylaxis and vascular permeability measurements. Measurement of body temperature during anaphylaxis was performed using an implantable electronic transponder, inserted under the dorsal neck skin fold of isofluraneanesthetized mice at least 24 hours in advance of the start of anaphylaxis experiments. Twenty-four hours prior to induction of passive systemic anaphylaxis, mice were sensitized (i.v.) with $3 \mu \mathrm{g}$ DNP-specific $\operatorname{IgE}(0.2 \mathrm{ml}$ volume). Mice were subsequently challenged with $250 \mu \mathrm{g} \mathrm{Ag}\left(\mathrm{DNP}_{36}\right.$-HSA) or vehicle (saline solution). Alternatively, anaphylaxis was induced by a bolus of histamine ( $5 \mu \mathrm{mol}$ in $0.2 \mathrm{ml}$ saline), a concentration that induced similar body temperature decreases as those elicited by IgE/Ag. Unless otherwise indicated, injections were conducted on anesthetized mice $(2 \%$ isoflurane/98\% oxygen mix for 2-3 minutes) in a closed chamber. Basal body temperature was determined prior to the anaphylactic challenge, and changes after induction of anaphylaxis were measured using an electronic probe at 1 minute after induction and then at 5-minute intervals for a period of 60 minutes. Mice were subsequently euthanized, and blood was immediately drawn by cardiac puncture. Where indicated, S1P $(500 \mu \mathrm{M})$ in $0.2 \mathrm{ml}$ mouse albumin in saline or mouse albumin in saline alone $(0.2 \mathrm{ml})$ was injected 10 minutes after the histamine bolus. Vascular permeability measurements are described in the legend to Supplemental Figure 6.

Blood pressure measurements. Mice were anesthetized with isoflurane (2\%) and placed on a servo-controlled heating table that maintains body temperature at $37.5^{\circ} \mathrm{C}$. A self-drawn polyethylene catheter was inserted into the left femoral artery, and MAP was measured with a physiological pressure transducer (MLT844; AD Instruments) connected to the catheter line. The captured analog signal was transformed with PowerLab 4/25 (AD Instruments) into digital data and recorded with Chart 5 software. Continuous blood pressure measurements were averaged over 2-minute periods of acquisition, for a total of 30 minutes after administration of the histamine bolus. The effect of histamine on the overall 30-minute blood pressure observation period was determined by integration of the AUC and expressed as $\mathrm{mmHg} \times \mathrm{min}$.

Pulse oximetry measurements. Pulse oximetry data, including arterial oxygen saturation, pulse distension, and heart and breath rate, were recorded using the MouseOx pulse oximeter, with a collar clip sensor (STARR Life Sciences Corp.) in nonanesthetized (conscious) mice. A baseline measurement was done, and subsequent measurements were at 30,60, and 120 minutes after the histamine bolus. Values were recorded only after plethysmographic measurements showed stability.

GFR measurements. The GFR of anesthetized mice undergoing histamineinduced anaphylaxis was measured by FITC-inulin elimination kinetics as previously described (61). Briefly, 5 minutes after induction of anaphylaxis, mice were injected (i.v.) with $3.7 \mu \mathrm{l} \times$ body weight of $2.5 \%$ FITC-inulin (Sigma-Aldrich), and blood was drawn from the tail vein at 3, 7, 10, 15, 35, and 55 minutes after injection. Plasma fluorescence was determined with a fluorospectrometer (NanoDrop 3300; Thermo Scientific). The clearance of each individual mouse was calculated using a FITC-inulin standard, after a 2-phase exponential decay curve was performed.

Histamine clearance. To determine the clearance rate of histamine from plasma, blood was drawn via tail vein puncture into heparinized $5 \mu \mathrm{l}$ microcapillaries (Drummond Scientific) at 10, 20, 30, 60, and 120 minutes after the injection of histamine. After centrifugation, plasma was collected and histamine content was measured. Whenever possible, spot urine samples were collected at 30,60, and 120 minutes after histamine 
injection. Histamine levels were measured using a competitive histamine immunoassay kit (Beckman Coulter).

Lipid preparation and S1P measurements. S1P (Biomol) was prepared as a $1 \mathrm{mM}$ solution in methanol, divided into aliquots, and dried under $\mathrm{N}_{2}$ stream. Lipid aliquots were resuspended in $4 \mathrm{mg} / \mathrm{ml}$ mouse albumin (Sigma-Aldrich) in saline to yield concentrations of $500 \mu \mathrm{M}$ and brought into solution using a water bath sonicator. For measurement of S1P in the plasma, lipids were extracted under alkaline conditions as previously described (13). The aqueous phase containing S1P was treated with alkaline phosphatase to dephosphorylate S1P to sphingosine. Following lipid extraction in acid conditions, the generated sphingosine was isolated from the organic phase and quantified by an enzymatic assay using cell lysates from HEK293 cells overexpressing SphK1 as previously described (13).

Statistics. Statistical significance was determined using a 2-tailed Student's $t$ test, and statistical differences among the genotypes for various treatments were evaluated by 2-way ANOVA, as indicated in the legends to figures. A $P$ value of less than 0.05 was considered significant. Data are shown as mean \pm SEM.

1. Felix SB, Baumann G, Berdel WE. Systemic anaphylaxis--separation of cardiac reactions from respiratory and peripheral vascular events. Res Exp Med (Berl). 1990;190(4):239-252.

2. Galli SJ. Chair's introduction. Anaphylaxis. Novartis Found Symp. 2004;257:1-5.

3. Simons FE. 9. Anaphylaxis. J Allergy Clin Immunol. 2008;121(2 Suppl):S402-S407; quiz S420.

4. Blank U, Rivera J. The ins and outs of IgE-dependent mast-cell exocytosis. Trends Immunol. 2004; 25(5):266-273.

5. El-Shanawany T, Williams PE, Jolles S. Clinical immunology review series: an approach to the patient with anaphylaxis. Clin Exp Immunol. 2008; 153(1):1-9.

6. Rivera J, Proia RL, Olivera A. The alliance of sphingosine-1-phosphate and its receptors in immunity. Nat Rev Immunol. 2008;8(10):753-763.

7. Ammit AJ, et al. Sphingosine 1-phosphate modulates human airway smooth muscle cell functions that promote inflammation and airway remodeling in asthma. FASEB J. 2001;15(7):1212-1214.

8. Jolly P, Rosenfeldt H, Milstien S, Spiegel S. The roles of sphingosine-1-phosphate in asthma. $\mathrm{Mol}$ Immunol. 2002;38(16-18):1239-1251.

9. Idzko M, et al. Local application of FTY720 to the lung abrogates experimental asthma by altering dendritic cell function. J Clin Invest. 2006;116(11):2935-2944.

10. Sumi T, et al. Treatment with FTY720 during the induction or effector phase suppresses the development of experimental allergic conjunctivitis in mice. Cell Biol Int. 2009;33(4):534-541.

11. Prieschl EE, Csonga R, Novotny V, Kikuchi GE, Baumruker T. The balance between sphingosine and sphingosine-1-phosphate is decisive for mast cell activation after $\mathrm{F} \varepsilon \mathrm{c}$ receptor I triggering. J Exp Med. 1999;190(1):1-8.

12. Camerer E, et al. Sphingosine-1-phosphate in the plasma compartment regulates basal and inflammation-induced vascular leak in mice. JClin Invest. 2009; 119(7):1871-1879.

13. Olivera A, et al. IgE-dependent activation of sphingosine kinases 1 and 2 and secretion of sphingosine 1-phosphate requires Fyn kinase and contributes to mast cell responses. J Biol Chem. 2006;2 81(5):2515-2525.

14. Choi OH, Kim JH, Kinet JP. Calcium mobilization via sphingosine kinase in signalling by the FceRI antigen receptor. Nature. 1996;380(6575):634-636.

15. Olivera A, et al. The sphingosine kinase-sphingosine1-phosphate axis is a determinant of mast cell function and anaphylaxis. Immunity. 2007;26(3):287-297.

16. Jolly PS, et al. Transactivation of sphingosine-1phosphate receptors by FceRI triggering is required

\section{Acknowledgments}

The work herein was supported by the Intramural Research Programs of NIAMS and NIDDK, NIH. The authors thank the animal care programs of the Office of Science and Technology, NIAMS, and NIDDK for invaluable support during this work.

Received for publication July 31, 2009, and accepted in revised form February 17, 2010.

Address correspondence to: Ana Olivera or Juan Rivera, Laboratory of Molecular Immunogenetics, NIAMS-NIH, Building 10, Room 13C103, Bethesda, Maryland 20892, USA. Phone: 301.496.7592; Fax: 301.480.1580; E-mail: oliveraa@mail.nih.gov (A. Olivera) or juan_rivera@nih.gov (J. Rivera).

Susanne C. Diesner's present address is: Department of Pediatrics and Adolescent Medicine, Medical University of Vienna, Vienna, Austria. for normal mast cell degranulation and chemotaxis. J Exp Med. 2004;199(7):959-970.

17. Price MM, Kapitonov D, Allegood J, Milstien S, Oskeritzian CA, Spiegel S. Sphingosine-1-phosphate induces development of functionally mature chymase-expressing human mast cells from hematopoietic progenitors. FASEB J. 2009;23(10):3506-3515.

18. Igarashi J, Michel T. Sphingosine-1-phosphate and modulation of vascular tone. Cardiovasc Res. 2009; 82(2):212-220.

19. Means CK, Brown JH. Sphingosine-1-phosphate receptor signalling in the heart. Cardiovasc Res. 2009; 82(2):193-200.

20. Lee JF, et al. Balance of S1P1 and S1P2 signaling regulates peripheral microvascular permeability in rat cremaster muscle vasculature. Am J Physiol Heart Circ Physiol. 2009;296(1):H33-H42.

21. Makabe-Kobayashi Y, et al. The control effect of histamine on body temperature and respiratory function in IgE-dependent systemic anaphylaxis. J Allergy Clin Immunol. 2002;110(2):298-303.

22. Pumphrey RS. Lessons for management of anaphylaxis from a study of fatal reactions. Clin Exp Allergy. 2000;30(8):1144-1150.

23. Sheikh A, Shehata YA, Brown SG, Simons FE. Adrenaline for the treatment of anaphylaxis: cochrane systematic review. Allergy. 2009;64(2):204-212.

24. Miyajima I, Dombrowicz D, Martin TR, Ravetch JV, Kinet JP, Galli SJ. Systemic anaphylaxis in the mouse can be mediated largely through IgG1 and FcyRIII. Assessment of the cardiopulmonary changes, mast cell degranulation, and death associated with active or IgE- or IgG1-dependent passive anaphylaxis. J Clin Invest. 1997;99(5):901-914.

25. Dombrowicz D, Flamand V, Miyajima I, Ravetch JV, Galli SJ, Kinet JP. Absence of FcERI $\alpha$ chain results in upregulation of Fc $\gamma$ RIII-dependent mast cell degranulation and anaphylaxis - Evidence of competition between FceRI and FcyRIII for limiting amounts of $\mathrm{FCR} \beta$ and $\gamma$ chains. J Clin Invest. 1997; 99(5):915-925.

26. Roberts F, Calcutt CR. Histamine and the hypothalamus. Neuroscience. 1983;9(4):721-739.

27. Allende ML, et al. Mice deficient in sphingosine kinase 1 are rendered lymphopenic by FTY720. J Biol Chem. 2004;279(50):52487-52492.

28. Venkataraman K, et al. Vascular endothelium as a contributor of plasma sphingosine 1-phosphate. Circ Res. 2008;102(6):669-676.

29. Huwiler A, et al. Histamine increases sphingosine kinase- 1 expression and activity in the human arterial endothelial cell line EA.hy 926 by a PKC- $\alpha$ dependent mechanism. Biochim Biophys Acta. 2006; 1761(3):367-376.
30. Chrusch $\mathrm{C}$, et al. Histamine $\mathrm{H} 3$ receptor blockade improves cardiac function in canine anaphylaxis. Am J Respir Crit Care Med. 1999;160(4):1142-1149.

31. Felix SB, et al. Effects of histamine H1-receptor blockade on respiratory and cardiac manifestation of systemic anaphylaxis. Agents Actions. 1991; 33(3-4):349-358.

32. Forrest $\mathrm{M}$, et al. Immune cell regulation and cardiovascular effects of sphingosine 1-phosphate receptor agonists in rodents are mediated via distinct receptor subtypes. J Pharmacol Exp Ther. 2004;309(2):758-768.

33. Skoura A, Hla T. Regulation of vascular physiology and pathology by the S1P2 receptor subtype. Cardiovasc Res. 2009;82(2):221-228.

34. Allende ML, et al. S1P1 receptor expression regulates emergence of NKT cells in peripheral tissues. FASEB J. 2008;22(1):307-315.

35. Halpern BN, Neveu T, Wilson CW. The distribution and fate of radioactive histamine in the rat. J Physiol. 1959;147:437-449.

36. Sedor JR, Abboud HE. Actions and metabolism of histamine in glomeruli and tubules of the human kidney. Kidney Int. 1984;26(2):144-152.

37. Abboud HE. Catabolism of histamine in the isolated glomeruli and tubules of the rat kidney. Kidney Int. 1983;24(4):534-541.

38. Urtz N, et al. Early activation of sphingosine kinase in mast cells and recruitment to FceRI are mediated by its interaction with Lyn kinase. Mol Cell Biol. 2004;24(19):8765-8777.

39. Lieberman P, et al. Epidemiology of anaphylaxis: findings of the American College of Allergy, Asthma and Immunology Epidemiology of Anaphylaxis Working Group. Ann Allergy Asthma Immunol. 2006;97(5):596-602.

40. Morrow JD, Margolies GR, Rowland J, Roberts LJ 2nd. Evidence that histamine is the causative toxin of scombroid-fish poisoning. N Engl J Med. 1991; 324(11):716-720.

41. Maintz L, Novak N. Histamine and histamine intolerance. Am J Clin Nutr. 2007;85(5):1185-1196.

42. Hershko AY, Dranitzki Z, Ulmanski R, Levi-Schaffer F, Naparstek Y. Constitutive hyperhistaminaemia: a possible mechanism for recurrent anaphylaxis. Scand J Clin Lab Invest. 2001;61(6):449-452.

43. MacGlashan D Jr. Histamine: a mediator of inflammation. J Allergy Clin Immunol. 2003; 112(4 Suppl):S53-S59.

44. Akdis CA, Jutel M, Akdis M. Regulatory effects of histamine and histamine receptor expression in human allergic immune responses. Chem Immunol Allergy. 2008;94:67-82.

45. Toubanaki DK, Christopoulos TK, Ioannou PC, Flordellis CS. High-throughput chemiluminomet- 
ric genotyping of single nucleotide polymorphisms of histamine, serotonin, and adrenergic receptor genes. Anal Biochem. 2009;385(1):34-41.

46. Zampeli E, Tiligada E. The role of histamine $\mathrm{H} 4$ receptor in immune and inflammatory disorders. Br J Pharmacol. 2009;157(1):24-33.

47. Dvorak AM. Mast cell-derived mediators of enhanced microvascular permeability, vascular permeability factor/vascular endothelial growth factor, histamine, and serotonin, cause leakage of macromolecules through a new endothelial cell permeability organelle, the vesiculo-vacuolar organelle. Chem Immunol Allergy. 2005;85:185-204.

48. Leach L, Eaton BM, Westcott ED, Firth JA. Effect of histamine on endothelial permeability and structure and adhesion molecules of the paracellular junctions of perfused human placental microvessels. Microvasc Res. 1995;50(3):323-337.

49. Bolz SS, et al. Sphingosine kinase modulates microvascular tone and myogenic responses through activation of RhoA/Rho kinase. Circulation. 2003; 108(3):342-347.

50. Keller M, et al. Sphingosine kinase functionally links elevated transmural pressure and increased reactive oxygen species formation in resistance arteries. FASEB J. 2006;20(6):702-704.

51. Peter BF, et al. Role of sphingosine-1-phosphate phosphohydrolase 1 in the regulation of resistance artery tone. Circ Res. 2008;103(3):315-324.

52 . Kono M, et al. The sphingosine-1-phosphate receptors S1P1, S1P2, and S1P3 function coordinately during embryonic angiogenesis. J Biol Chem. 2004 279(28):29367-29373.

53. Singleton PA, Dudek SM, Chiang ET, Garcia JG. Regulation of sphingosine 1-phosphate-induced endothelial cytoskeletal rearrangement and barrier enhancement by S1P1 receptor, PI3 kinase, Tiam1/Rac1, and alpha-actinin. FASEB J. 2005; 19(12):1646-1656.

54. Lorenz JN, Arend LJ, Robitz R, Paul RJ, MacLennan AJ. Vascular dysfunction in S1P2 sphingosine 1-phosphate receptor knockout mice. Am J Physiol Regul Integr Comp Physiol. 2007;292(1):R440-R446.

55. Sanchez T, Skoura A, Wu MT, Casserly B, Harrington $\mathrm{EO}, \mathrm{Hla}$ T. Induction of vascular permeability by the sphingosine-1-phosphate receptor-2 (S1P2R) and its downstream effectors ROCK and PTEN. Arterioscler Thromb Vasc Biol. 2007;27(6):1312-1318.

56. Ohmori T, et al. Sphingosine 1-phosphate induces contraction of coronary artery smooth muscle cells via S1P2. Cardiovasc Res. 2003;58(1):170-177.

57. Davis MD, Clemens JJ, Macdonald TL, Lynch KR. Sphingosine 1-phosphate analogs as receptor antagonists. J Biol Chem. 2005;280(11):9833-9841.

58. Tauseef M, et al. Activation of sphingosine kinase-1 reverses the increase in lung vascular permeability through sphingosine-1-phosphate receptor signaling in endothelial cells. Circ Res. 2008;103(10):1164-1172.

59. Mizugishi K, Yamashita T, Olivera A, Miller GF, Spiegel S, Proia RL. Essential role for sphingosine kinases in neural and vascular development. Mol Cell Biol. 2005;25(24):11113-11121.

60. Kono M, et al. Deafness and stria vascularis defects in S1P2 receptor-null mice. J Biol Chem. 2007; 282(14):10690-10696.

61. Qi Z, et al. Serial determination of glomerular filtration rate in conscious mice using FITCinulin clearance. Am J Physiol Renal Pbysiol. 2004; 286(3):F590-F596 